\title{
LA ACTUAL NARRATIVA INFANTIL Y JUVENIL ESPAÑOLA
}

\author{
Magdalena Vásquez Vargas \\ La literatura, como el arte en general, como la cultura, como toda \\ marca humana, está instalada en esa frontera. Una frontera espesa, que \\ contiene de todo, e independiente: que no pertenece al adentro, a las \\ puras subjetividades, ni al afuera, el real o mundo objetivo. \\ La frontera indómita. \\ Graciela Montes.
}

\section{RESUMEN}

\begin{abstract}
Este artículo aborda el desarrollo de la narrativa infantil y juvenil española posterior a la Guerra Civil. Presenta un panorama amplio de las obras y los autores más representativos y destaca los rasgos característicos, principalmente de la narrativa producida en el periodo del restablecimiento del régimen democrático.
\end{abstract}

\begin{abstract}
This article approaches the Spanish infantile and youthful narrative development after the Civil War. It showes a wide view of the most representative literary pieces and authores. It mainly highlights the features of the narrative produced in the democratic regimen restablishment period.
\end{abstract}

\section{Introducción}

La literatura infantil y juvenil española desde la conclusión de la Guerra Civil hasta nuestros días ofrece un panorama muy amplio, complejo ${ }^{1}$ e interesante. Diversos factores de orden político, social, cultural, económico y educativo han incidido notablemente en la evolución que ha experimentado. La vasta producción de obras que ha habido genera dificultades para establecer rasgos comunes que permitan emitir criterios con una validez general. No obstante, lo que se pretende en este artículo es elaborar un panorama general de la narrativa infantil y juvenil española a partir de la Guerra Civil, centrando la atención en las dos últimas décadas, las cuales coinciden con el restablecimiento del régimen democrático, y determinar una serie de características y conclusiones que sirvan como marco contextual o de referencia donde ubicar las obras producidas en dicho periodo. Lo anterior abre un espacio para investigar las particularidades de la obra de cada autor, así como aspectos más sutiles relacionados con elementos estéticos e ideológicos. 
En un primer apartado, se estudia el impacto generado por la Guerra Civil Española en la narrativa infantil y juvenil y se describen los cambios más importantes que esta narrativa experimentó en la posguerra, a pesar de la difícil situación por la que atravesaba el país. Seguidamente, se analizan las transformaciones sociales, económicas, políticas y culturales que provocaron el restablecimiento del régimen democrático y sus repercusiones en el nivel temático y formal de las obras.

Es conveniente anotar que el género narrativo, en relación con la poesía y el drama, ha experimentado un notable desarrollo. En sus diferentes estudios sobre la literatura infantil y juvenil española, Teresa Colomer (1990) opina que los géneros poético y dramático han sido cultivados precariamente en la actualidad. Otros críticos como Mercedes Gómez del Manzano, Jaime García Padrino, Manuel Vieites y Caterina Valriu confirman la posición de Colomer sin negar el aporte de los escritores que más han descollado ${ }^{2}$. Por ejemplo, Caterina Valriu (1995), refiriéndose más específicamente a la literatura catalana y sin presentar ningún juicio sobre la calidad de la poesía y del teatro, ha hecho hincapié en que se trata de géneros minoritarios, que en comparación con la narrativa no han alcanzado un desarrollo similar y cree que no lo alcanzarán: "La poesia i el teatro són —i pel que sembla seguiran essent durant molt de temps gèneres minoritaris".

Aunque no es tema de este artículo, merece la pena emprender otra investigación para determinar el aporte que autores como Gloria Fuertes, Clemencia Laborda, Jaime Ferrán, Marina Romero, Adriano del Valle, Concha Lagos, Joaquín González Estrada, Carmen Conde, Antonio Gómez Yebra, Antonio Mejías, Carmen Bravo Villasante, Cristóbal Romero, Carlos Murciano y otros han dado y están dando a la actual poesía infantil española. Lo mismo puede pensarse con respecto a autores como Carmen Vázquez Vigo, Consuelo Armijo, Ricardo Alcántara, Luis Matilla, Gloria Fuertes, Carmen Conde, Alejandro Casona, Concha Castroviejo, Carmen Bravo Villasante, Jesús López Pacheco, Ángeles Gasset, Fernando Almena, Vicente Vizcaíno, Jorge Ponsada, Miguel Medina, José Luis Alonso de Santos, entre otros, quienes tienen una importante producción de obras teatrales dirigidas a los niños, que aún no han sido valoradas ampliamente. Podría afirmarse a priori que hay razones que no son estrictamente literarias, las cuales intervienen en la forma en que han sido abordados tanto la poesía como el teatro infantil. El apoyo editorial y los premios se han orientado en una mayor difusión del género narrativo; se continúan editando los poetas y dramaturgos consagrados, lo cual limita las posibilidades a los jóvenes y, además, ambos géneros han sido utilizados principalmente con fines pedagógicos. En fin, queda aquí abierto un interesante campo de investigación, a sabiendas de que existen algunos críticos como Pedro Cerrillo, Juan Cervera, Isabel Tejerina, Jaime García Padrino y Victoria Sotomayor Sáez 3 , quienes se han venido preocupando por estos temas.

\section{La ruptura marcada por la Guerra Civil}

En las tres primeras décadas del siglo veinte, y principalmente en los años previos a la Guerra Civil, los escritores que se dirigían a los niños fueron muy innovadores, cultivaron temas de distinta índole y experimentaron con interesantes formas que permitían un acercamiento espontáneo al mundo infantil. Dieron énfasis al rescate del folclore, a la recreación del mundo cotidiano y de la fantasía y exploraron con plena libertad las líneas que se podían derivar de 
estas corrientes, de manera que el panorama de la literatura infantil era prometedor. Las obras de Antoniorrobles (seudónimo de Antonio Joaquín Robles Soler), Manuel Abril y Elena Fortún (seudónimo de Encarnación Aragoneses Urquijo), solo para citar algunos nombres, muestran gran originalidad y renovación en cuanto al tratamiento de los temas y presentan al niño un mundo sin condicionantes ideológicos tan fuertes como los que se apreciaron en la guerra y en la posguerra. Ellos, sobre todo Antoniorrobles, abogaban por una narrativa que explorara las múltiples posibilidades del juego entre la realidad y la fantasía ${ }^{4}$ y empleaban diversos recursos retóricos para sensibilizar al niño en temas o valores que son universales y que no se restringen a clases, razas o situaciones. Igualmente, procuraban construir un universo narrativo en el que se presentara al niño desde su individualidad y no se viera como un sujeto en formación que debía ser constantemente corregido y orientado por los adultos. Pretendían que fuera el auténtico protagonista, con toda la independencia que caracteriza a la niñez. Esto puede apreciarse muy bien en personajes como Celia, Cuchifritín y Matón-Kikí, creados por Elena Fortún.

Ya propiamente en el periodo de la Guerra Civil, los propósitos utilitarios e ideológicos se antepusieron a los formativos y recreativos de la literatura infantil y se produjo una ruptura y una desvinculación con las tendencias que predominaron en las tres primeras décadas del siglo veinte:

\footnotetext{
Aquel alentador panorama anterior en las creaciones literarias dedicadas al niño, consolidado gracias a la renovación experimentada por esa literatura durante los años inmediatamente anteriores a 1936, quedó truncado de raíz a partir de aquel 18 de julio. Pero, además, después del mes de abril de 1939, las obras literarias dedicadas al niño serían ya radicalmente distintas a las aparecidas en la década anterior ${ }^{5}$.
}

Además, la libertad de expresión que caracterizó los años anteriores y que estaba garantizada en la Constitución Española de 1931, en el título III (Derechos y deberes de los españoles), capítulo primero (Garantías individuales y políticas), artículo 34, se vio profundamente afectada. Este artículo proclamaba lo siguiente:

\footnotetext{
Toda persona tiene derecho a emitir libremente sus ideas y opiniones valiéndose de cualquier medio de difusión, sin sujetarse a la previa censura.

En ningún caso podrá recogerse la edición de libros y periódicos sino en virtud de mandamiento de juez competente.

No podrá decretarse la suspensión de ningún periódico sino por sentencia firme ${ }^{6}$.
}

Las garantías individuales y la libertad de prensa fueron, pues, sometidas a la censura. Se aplican diversas medidas restrictivas y prohibitivas, y la literatura, como manifestación individual, publicada generalmente en forma de libro o dispersa en revistas, debía pasar por dicho filtro. Si un escritor aludía a la guerra, se veía obligado a hacerlo en forma velada, como en los cuentos "Palomitas de Botón/ de paz y de guerra son", "Cierto niño, en cierta guerra/ con tigres labró la tierra", "El poderoso influyentel y los tres magos de Oriente", "Don Nubarrón en los refugios" de Antoniorrobles, en los cuales se aprecian conceptos ideológicos radicalmente opuestos al fascismo (García Padrino 1992: 424-34) de un modo explícito. La carta que Elena Fortún le dirigía a Inés Field en 1948 ilustra muy bien los temores y cuidados que la censura implicaba:

Es posible también que haya algunos libros que no deje pasar la censura. Es fácil conocerlos. Todos en los que se trata de la religión sin el debido respeto o que tengan asuntos escabrosos. No creo que haya nada de esto entre mis libros, pero míralo por si acaso ${ }^{7}$. 
Sin duda, la censura funcionaba como un mecanismo de exclusión de todos aquellos elementos subversivos para el sistema político, con lo cual las obras quedaban mutiladas o no se publicaban. Amalia Bermejo apunta que el papel de la censura fue crucial en todas las publicaciones para niños y destaca como lo más grave el hecho de que "trajo consigo la autocensura del escritor" (Bermejo 1999: 21). Este se vio obligado a acatar las normas morales y políticas; su trabajo creativo se oscurecía por las distintas barreras ideológicas que lo limitaban para expresarse con toda libertad.

En los años de la Guerra, prácticamente no hubo publicaciones para niños y solo unos pocos autores procuraron continuar con sus creaciones; pero las condiciones sociales, políticas e ideológicas se convirtieron en un poderoso factor adverso para la publicación y difusión de libros. Además, se mostraron muy preocupados por la situación que vivía España en ese momento y en algunos de los relatos, como lo hace Elena Fortún en "La ciudad de los tontos" y "Los dos hermanos", publicados en la Revista Crónica, en 1936 y 1937 respectivamente, aluden a la conmoción y al impacto que generaba la guerra. En este sentido, Jaime García Padrino considera fundamental el aporte de Elena Fortún, ya que presenta la guerra como un fenómeno cruel en sí mismo donde "el hombre, y en especial, el niño perdían su auténtica condición humana al ser víctimas de una lucha ni deseada ni comprendida"(1992: 445) ${ }^{8}$.

En los relatos publicados por Elena Fortún, se apreciaba la evolución del conflicto bélico y su concepción del niño, de la guerra y del ser humano. Ella exponía, apoyándose en la creación de alegorías (García Padrino 1992: 463), las características y consecuencias del enfrentamiento en que estaba inmerso el pueblo español y consideraba que la solidaridad, la armonía y la comprensión entre los hombres permitirían construir un mundo pacífico e igualitario. En realidad, el medio era hostil y denunciar en forma directa las atrocidades que estaban ocurriendo le generaba serios problemas a cualquier escritor.

Los años inmediatos a la conclusión de la Guerra están marcados por la pobreza material y cultural que hacía imposibles las ediciones y llevaba a que muchos autores dejaran de escribir para niños. La renovación que durante la Segunda República (1931-1936) había tenido la literatura infantil se desecha y no se le da continuidad. El afán por desarrollar plenamente la personalidad del niño dejó de ser prioritario porque en la posguerra lo que interesaba ante todo era difundir la ideología del poder imperante. Algunos críticos señalan que la posguerra desertizó culturalmente el país (Hendriks 1990: 13) pues cerró los caminos para la expresión auténtica de las vivencias y aspiraciones de los españoles.

Muchos escritores famosos se vieron obligados a exiliarse; las publicaciones solo debían hacerse en castellano y se estableció la censura hasta 1978, incluso (Colomer 1990: 139)9 . Según los lineamientos impuestos desde la oficialidad política, la literatura que se producía estaba limitada a ciertos ámbitos y temas y obligada a presentar una imagen homogénea de la cultura y de la nacionalidad españolas. Así, por ejemplo, la temática religiosa y el folclore popular alcanzan un gran predominio, como se ve en Marcelino Pan y Vino (1952) de José María Sánchez Silva ${ }^{10}$, que ha alcanzado un lugar cumbre en la literatura infantil española. No se detiene este libro en abordar directamente el contexto social e histórico sino que propone una religión muy cercana a los niños, muy humana y afectuosa, en la que el amor y la fraternidad son los ejes principales. Sin embargo, tampoco estuvo exento de censura, pues llegó a ser considerado como irreverente y blasfemo ${ }^{11}$ contra la religión católica. 
No solo lo que se escribía estaba sometido a la censura. También los textos que se leían debían responder a los intereses del sistema político, o al menos, no atentar contra él. Josefina Rodríguez Aldecoa (1983: 18) sostiene que lo que se leía en España en el periodo franquista era una literatura de evasión ${ }^{12}$ que llevaba al lector al disfrute de mundos exóticos pero le hacía olvidar su realidad, en muchos casos precaria y miserable. Entre los autores que se leían en dicho periodo están Louis Bromfield (Estados Unidos, 1896-1956), Daphne du Mourier (Inglaterra, 1907), Lajos Zilahy (Hungría, 1891-1975) y Vicky Baum (Austria, 1888-1960).

Las creaciones literarias infantiles no podían transgredir el sistema dominante y, por ello, se observa "un notable predominio de la exaltación de los valores familiares, dentro de un modelo de vida presidido por una marcada orientación religiosa y por un obligado canto a los valores históricos del pasado imperial de España" (García Padrino 1992: 498-9). Se observa una tendencia a utilizar algunas figuras "importantes" de la historia en las narraciones, para ejemplificar diversos ámbitos de la vida social y tomarlas como modelo. Obviamente, dentro de estos parámetros también interesaba transmitir modelos sociales, de carácter moral y religioso (católicos). En general, las obras se mantuvieron fieles a la ideología dominante y se convirtieron en importantes mecanismos de difusión de las supuestas bondades del orden social establecido.

Esta adecuación de la literatura a fines políticos e ideológicos tuvo implicaciones serias en cuanto a la imagen de la realidad, la cual, así construida, resulta parcial, fragmentaria y falseada, a la vez que los recursos retóricos utilizados se tornaban repetitivos y debían responder a ciertas ideas preconcebidas y preestablecidas. A lo anterior se debe sumar el propósito educativo que se le inculcó a la literatura y que pretendía formar individuos ejemplares en una España que había sido Patria de hombres ilustres. Como consecuencia de las limitaciones impuestas por el orden ideológico y político, muchos de los protagonistas infantiles solían adoptar comportamientos clichés que los convirtieron en modelos para los demás ${ }^{13}$. Las obras Hombres de hoy (1948) y Fin de carrera (1951) de Montserrat del Amo ilustran también esta preocupación pedagógica. En definitiva, los escritores vieron limitadas sus posibilidades de ofrecer al niño un mundo más amplio, dinámico, diverso y auténtico.

\section{Nuevas condiciones para un cambio}

En los años posteriores a la guerra, la literatura infantil y juvenil española se mantuvo distante de las tendencias que en este campo se estaban desarrollando en el resto de los países europeos (Colomer 1990: 140), lo cual hacía que los escritores se encontraran al margen de las nuevas orientaciones formales y temáticas de la literatura europea del momento. Sin embargo, ya en la década de los sesenta, se produjo un cambio sustancial en este sentido, pues se generó una apertura hacia las corrientes de la literatura infantil europea. Además de ello, se aceptó la publicación en otras lenguas que no fuera el castellano, se impulsó la creación de revistas y premios y se apreció en las obras una importante renovación temática y un predominio del realismo.

Por otra parte, según García Padrino (1992: 513), alrededor del año 1955 hay un cambio importante en la vida económica, política e intelectual que incide favorablemente en el desarrollo de la literatura infantil. Se da una apertura internacional, básicamente por parte de los países que vencieron en la Segunda Guerra Mundial; se aprecia una ligera mejoría económica y hay muestras de una liberalización intelectual. Los escritores manifiestan su iniciativa 
por renovar los diferentes géneros literarios infantiles y también se instituyen premios y estímulos editoriales para la creación infantil.

En el año 1951, la Dirección General de Bellas Artes convoca un concurso para premiar la mejor colección de libros infantiles; en ese mismo año, se realizan varias exposiciones, se publican catálogos bibliográficos y se convoca el Premio Nacional de Literatura; en 1958, se crea el Premio Lazarillo; en 1961, aparece el primer número de El lazarillo del lector, revista que se encargaría de publicar reseñas y materiales críticos sobre la producción literaria infantil, tanto de autores consagrados como de los nuevos valores; en 1962, la Comisión Católica Española para la Infancia crea un premio para distinguir la mejor obra publicada en cuanto a ilustración y edición; en 1962, en Cataluña, aparece la Revista Cavall Fort y en 1963, también en Cataluña se reforma la Revista L'infantil y se establecen los premios Folch i Torres y Joaquim Ruyra.

Otro elemento que demuestra la importancia que se otorgó a la literatura infantil lo constituye la publicación de varias historias de la literatura infantil que daban cuenta de autores, obras y principales tendencias. Solo como ejemplo, véanse Literatura infantil española (1957) de Carolina Toral, Historia de la literatura infantil española (1959) y Antología de la literatura infantil en lengua española (1962), estas dos últimas de Carmen Bravo Villasante. El aporte de Toral y, sobre todo, el de Bravo Villasante resultan de una enorme importancia porque recogen y ordenan los autores y las obras más representativos hasta la fecha en que se publican estos libros; contribuyen a conformar una visión amplia del proceso que ha tenido esta literatura a lo largo de su historia y le confieren un lugar significativo dentro de la cultura y la literatura españolas, que tiende a superar la marginalidad de que ha sido objeto por los mismos historiadores de esta literatura.

Este resurgimiento de la literatura infantil vino acompañado de una importante renovación en el campo editorial. El dinamismo y la difusión que las editoriales otorgaron a la literatura infantil fueron determinantes para el desarrollo posterior. Diversas editoriales se encargaron de promocionar la literatura infantil en sus más variados ámbitos. Destacan la Editorial Aguilar, Ediciones Cid, Editorial Doncel, Editora Nacional, Ediciones La Galera, Santillana, Ediciones Anaya y Editorial Lumen. García Padrino (1992: 522) sintetiza muy bien dicha labor y al mismo tiempo señala que, al finalizar la década de los sesenta, se impone de nuevo y fuertemente la censura:

\begin{abstract}
Aquellos años sesenta fueron, por lo tanto, un periodo de notable incremento en la producción de las publicaciones infantiles. A esas iniciativas editoriales hay que añadir la creación de una Comisión Asesora de Publicaciones Infantiles (1962) y la posterior Ley de Prensa e Imprenta (1964), que permitió una cierta liberalización de la producción del libro, cuya regulación se completaría con el Estatuto de Publicaciones Infantiles y Juveniles (1967). No obstante, los cambios en las actitudes y comportamientos sociales iban por delante de tales normas; al iniciarse los años setenta, eran ya claras las quejas y críticas hacia la exigencia y los criterios de la censura previa para las publicaciones infantiles ${ }^{14}$.
\end{abstract}

\title{
4. La transición (de la década de los sesenta)
}

En la década de los sesenta, se observan importantes intentos de renovación temática y estética, a lo cual se suma el predominio de una narrativa de carácter realista. Se incorporan nuevos temas y se modifica el enfoque de los anteriores; además, se utilizan nuevos recursos retóricos, como el humor, el barroquismo y los símbolos, que permiten presentar el universo infantil desde otros ángulos, así como la aparición del relato autobiográfico y la forma epistolar que 
alcanzan gran relevancia. Hay un propósito claro de renovación e incluso editoriales como Doncel se encargaron de concretarlo en géneros específicos como el cuento (Gómez del Manzano 1987: 63). Joaquín Aguirre y Miguel Buñuel, desde la colección La Ballena Alegre, promueven ese espíritu renovador que fue acogido por varios escritores, entre ellos José María Sánchez Silva, Ana María Matute, Rafael Morales y el mismo Miguel Buñuel.

No obstante lo anterior, la narrativa con orientación realista de alguna manera replegó el lenguaje a un segundo plano para denunciar con prioridad las contradicciones que encerraba el sistema político. José María Martínez Cachero, haciendo referencia a la novela española en general, señala que la narrativa realista que se produjo en este periodo se agotó pronto y encontró una crítica fácil de parte del sistema porque los escritores se exponían a ser presentados como incapaces de dar un tratamiento artístico al lenguaje (Martínez Cachero 1985: 263) y su proyecto de presentar la literatura como arma de combate fracasó.

Las obras con ambientación realista (Colomer 1990: 141) se imponen y coexisten con aquellas que siguen reproduciendo la ideología del sistema dominante. En cierto modo, se abren algunos espacios para la expresión de una sociedad aquejada por problemas como la delincuencia, la emigración hacia otros países europeos y las vicisitudes de la vida en los suburbios, y ya no se presenta con la misma fuerza la imagen idílica de la sociedad, sino el acontecer diario con sus dificultades y penurias. Tampoco se puede hablar de una literatura que rompe totalmente con la línea ideológica anterior. Muchos de los personajes siguen siendo caracterizados en forma plana y no se renuncia totalmente a una orientación pedagógica. Algunos de los autores más representativos de este momento son Carmen Kurtz, Rafael Morales, Tomás Salvador, Angela Ionescu, Carmen Vázquez Vigo, Juan A. de Laiglesia, Gloria Fuertes, Jaime Ferrán, Isabel Molina Llorente, Ana María Matute, Montserrat del Amo, Emilio Texidor, Pilar Molina Llorente, Marta Osorio y Francisco Candell, entre otros.

No puede afirmarse en términos absolutos que las obras de estos autores se reduzcan a un determinado tema o enfoque. Se trata de tendencias predominantes. Incluso hay autores que recrean el pasado histórico, como lo hacen Joaquín Aguirre en El juglar del Cid (1960) e Isabel Molina en Las ruinas de Numancia (1964), y otros que prefieren la ciencia ficción como Tomás Salvador en Marsuf, el vagabundo del espacio (1962). En todo caso, la narrativa que se produce en este momento de la posguerra se separa relativamente de la producida en los años inmediatos a la finalización de la guerra:

\footnotetext{
Quizá los cambios más notables en los tratamientos temáticos, con respecto a la anterior postguerra, correspondieron a los asuntos donde se planteaban aspectos de una realidad religiosa y a los modos de presentar las leyendas y determinados acontecimientos históricos. En los primeros ya no se buscaba el tono hagiográfico ni la exaltación de ejemplificantes virtudes alejadas de la auténtica personalidad infantil. Del mismo modo, en los temas históricos no se adoptaba un tono épico ni grandilocuente para exaltar un pasado glorioso e imperial (García Padrino 1992: 534).
}

Los pocos cambios presentados en la vida social, económica y cultural evidencian el tránsito de una sociedad homogénea y heroica, pero en el fondo resquebrajada, a una sociedad más abierta que fija su mirada en los problemas del presente y no en las viejas glorias. Así, también se aprecian los síntomas de una nueva forma de hacer literatura con la que se pretende recuperar el mundo infantil desde múltiples perspectivas y la idea de una literatura al servicio de los intereses ideológicos coyunturales empieza a quedarse anclada en el tiempo. Los 
autores, sin dejar de referirse a la realidad española, exploran nuevos ambientes y buscan una literatura más universal, como la que se está produciendo en otros países europeos, para lo cual se hace necesaria la utilización de nuevas técnicas narrativas.

Como ha podido notarse, ha existido un interés creciente y un auge relativo de las narraciones dirigidas a los niños. Hay un despertar que se revela en la proliferación de escritores, en la apertura temática, en mejores condiciones para editar y en un distanciamiento de las posiciones ideológicas e inclusive estéticas que predominaron durante las tres décadas anteriores. En el horizonte aparecen los signos de un nuevo desarrollo de la literatura infantil.

En síntesis, en esta década se observan tres orientaciones en la narrativa infantil: 1) aquella que sigue manteniendo un fin ideológico de reproducción del sistema y que parece ir entrando en decadencia, 2) aquella que pretende mostrar la realidad social y denunciar los problemas que enfrenta la población y 3) aquella que encarna una naciente renovación. Las dos primeras tuvieron un pecado común: relegar el lenguaje a un segundo plano. Por esta razón, no llegaron a alcanzar mayor trascendencia. En el momento en que los escritores toman conciencia de que la literatura vale por su calidad como artificio y no por servir a fines ajenos, se producen los primeros intentos de renovación que alcanzarán eco en los primeros años de la democracia. Se dan así los primeros pasos hacia el camino de la libertad, elemento fundamental para el desarrollo de las potencialidades creativas.

\section{La narrativa infantil española a partir de la década del setenta}

A partir de la década del setenta, y fundamentalmente después de la caída del régimen franquista (1975), la narrativa infantil española experimenta un interesante y acelerado cambio que la conduce por diversos senderos. La nueva situación política propicia la expresión libre de los creadores y abre las posibilidades para una representación amplia y democrática de los diversos sectores sociales y culturales. Se rompen las barreras ideológicas que habían limitado la producción literaria y el crecimiento económico se empieza a sentir en un aumento cuantitativo y cualitativo de las ediciones, así como, en general, en la promoción y difusión de la narrativa infantil.

Hay una notable apertura hacia las tendencias literarias que están en boga en Europa y producto de ello se editan y traducen importantes autores como Gianni Rodari (Italia, 19201981), María Gripe (Suecia, 1923), Roald Dahl (Gales, 1916-1990), Christine Nöstlinger (Austria, 1936), Michael Ende (Alemania, 1924-1995), Maurice Sendak (Estados Unidos, 1928). Los libros de estos autores tienen gran acogida por el público infantil y representan para los españoles la posibilidad de entrar en contacto con la literatura infantil mundial más representativa del momento y procurar así situarse a la vanguardia. Las obras se enmarcan en dos grandes tendencias estéticas: el realismo y la fantasía. Los autores se inclinan por una o por la otra, según el propósito que se plantean y los gustos de los niños. Nuevas temáticas y nuevos enfoques caracterizan las obras que se producen. Los autores reconocen el valor estético de los recursos retóricos y eso los lleva a efectuar innovaciones formales, que dan a la actual narrativa infantil española un lugar muy significativo dentro de la literatura infantil europea. 


\subsection{Un nuevo sistema político: un ambiente dinámico y plural}

El fin de la dictadura en 1975 marca también la apertura definitiva del régimen democrático. Por esta razón, los esfuerzos de los españoles se canalizan hacia un hecho capital: la modernización política. Esta se alcanza con la promulgación de la Constitución Española de 1978, que garantiza un orden social, jurídico y político que hará cambiar sustancialmente la historia española y determinará nuevas formas de convivencia y desarrollo. En los años ochenta se aprecian notables transformaciones sociales y económicas, como lo señalan Lamo, Pardo y Tusell (1996: XV):

\footnotetext{
...plena incorporación de España a Europa; renovación de la economía; brutales, casi pendulares, cambios demográficos; drásticas transformaciones en la composición de los hogares y las familias; ampliación extraordinaria de la educación en todos sus niveles y de un sistema de ciencia-tecnología; y, finalmente, desarrollo de Estado de bienestar y de un sistema de protección social en pensiones, desempleo y sanidad.
}

El régimen democrático rompe con el estatismo que había caracterizado la sociedad y se ingresa a un sistema de vida más activo y dinámico en el que se garantiza la libertad de expresión y el respeto por las ideas de los demás ciudadanos. Se alcanzan altos niveles de desarrollo y, en el ámbito político, también se concreta un cambio trascendental. Se reconoce la coexistencia cultural entre las distintas literaturas de España y ello permite la recuperación de las raíces culturales de las principales regiones o nacionalidades que integran España: Galicia, Cataluña y el País Vasco se integran al proceso literario español y, al mismo tiempo, proponen estrategias o alternativas de desarrollo particular de la literatura infantil en cada una de estas regiones. Esto ha llevado a que los elementos folclóricos y representativos de la realidad cultural e incluso geográfica sean motivo recurrente en la literatura que se produce. Por ejemplo, libros como: El fuego de los pastores (1987) de Concha López, Hubo una vez otra guerra (1988) de Luis A. Puente y Fernando Lalana y El niño que vino con el viento (1986) de Juan Farias tratan el paisaje y las costumbres de Andalucía, Aragón y Galicia, respectivamente.

De esta manera, el restablecimiento de la democracia resulta clave para la literatura y, por lo tanto, también para la narrativa infantil y trae consecuencias positivas en el ambiente cultural. Como producto del desarrollo económico, se fortalecen el mercado, la edición y difusión del libro infantil. Por otra parte, la apertura hacia los clásicos europeos y americanos, que se apoya en constantes traducciones, plantea perspectivas más amplias y una nueva valoración de la literatura que se está publicando.

La aparición de una multiplicidad de escritores, justificada en mucho por el cambio de sistema político, hace posible el rescate de las raíces de la identidad española y forja una nueva imagen colectiva. Los rasgos de las distintas identidades se constituyen en motivos de escritura literaria, pues se reivindican la fantasía, la complejidad de las relaciones personales, los conflictos vitales, la memoria histórica y, sobre todo, el poder de la literatura frente a la buena voluntad educativa que se evidenció en las obras de los años anteriores.

Así, la transformación notoria que España ha experimentado en los últimos años ha incidido fuertemente en la literatura infantil, pues ha generado un nuevo contexto en el cual la modernización, en la mayoría de los ámbitos y sectores del país, ha sido fundamental en la evolución de los modelos literarios y culturales. Los cambios sociales, históricos y políticos han repercutido en la aparición y el fomento de valores como la solidaridad, la tolerancia, la 
libertad, la autonomía (Colomer 1999: 138) al mismo tiempo que se presenta una visión crítica del contexto social y se tratan temas novedosos como la industrialización, la coexistencia de múltiples culturas, la estructura familiar y social y la tecnología.

\subsection{El realismo y la fantasía}

El realismo y la fantasía siempre han estado presentes en la literatura infantil. Ha habido épocas en las que se acentúa el predominio de una de estas tendencias, pero, de manera complementaria, ambas han permitido captar y expresar integralmente el universo del niño. Históricamente, la fantasía ha sido objeto de marginación, pues se ha considerado como trivial en comparación con el realismo, al que se le atribuye un carácter serio y útil, especialmente cuando la literatura ha estado al servicio de otros fines (pedagógicos, psicológicos, ideológicos, etc.) como ocurrió en la posguerra española y después de la Segunda Guerra Mundial. Sin embargo, la fantasía aporta valiosos elementos para la comprensión de la psicología humana y de la vida, y contribuye así a transformarla, quizá más que las obras realistas, que muchas veces se limitan a mostrarla en sus facetas exteriores ${ }^{15}$. En resumidas cuentas, realismo y fantasía son dos modos de aproximación a la realidad, cada uno con una estética y con unos recursos específicos. Se trata sobre todo de un juego de predominios, justificado muchas veces por las mismas condiciones históricas y políticas, y por los gustos culturales de un determinado momento.

La narrativa infantil producida en la postguerra respondía de forma particular al contexto histórico político, pues estaba llamada, por razones ideológicas, a reproducir aquellos elementos que eran fundamentales para la conservación del sistema. La década de los sesenta se caracterizó por la aparición de temas vinculados con la realidad del país. Los autores trabajaron algunos elementos que mostraban las principales contradicciones del sistema político y las condiciones marginales en que vivía un alto porcentaje de la población, lo que llevó a crear un ambiente propicio para la producción de obras de carácter realista. Por ejemplo, Paulina (1969) de Ana María Matute, Color de fuego (1964) de Carmen Kurtz, "Las nueces", relato incluido en De un país lejano (1962) de Ángela Ionescu. A partir de los setenta, con el nuevo sistema político, los autores se encontraron con más libertad e incursionaron en formas narrativas múltiples, unas propias de la corriente fantástica y otras de la realista.

En el nivel argumental, con su respectiva implicación estética, el realismo y la fantasía han sido las dos caras principales de la actual narrativa infantil y juvenil española. Francisco Cubells, en el libro Corrientes actuales de la narrativa infantil y juvenil española en lengua castellana (1990), subdivide la fantasía en relato maravilloso (o cuento de magia o hadas), relato fantástico (o de realismo mágico), non-sense ${ }^{16}$ (o superrealismo infantil) y relato de anticipación (o de ciencia ficción). Dentro del realismo ubica las novelas de aventuras ${ }^{17}$ y el realismo cotidiano.

Las obras consideradas fantásticas parten de asuntos o problemas reales a los que se le incorporan elementos mágicos o maravillosos. No prescinden de una crítica social seria, como bien afirma José Antonio del Cañizo (1990: 32), para quien el género fantástico no se desvincula de la realidad histórica y social, pues en él se puede plantear cualquier tema haciendo uso de elementos creativos como el juego, el humor, la poesía, etc. También Jordi Sierra i Fabra (1990: 39), creador de relatos de ciencia ficción sostiene que este género surge gracias 
a una percepción muy clara que el autor tiene de la realidad y que es plasmada en la obra literaria no como un fin inútil, sino cargado de humanismo.

Algunas de las obras más destacadas de la narrativa fantástica son: La guía fantástica (1977) de Joles Sennell; Mercedes e Inés o cuando la Tierra gira al revés (1980) de Consuelo Armijo; Las manos en el agua (1981) de Carlos Murciano; El extraño adiós de Oriel Munro (1982), La noche del Viajero Errante (1984), El talismán del Adriático (1988), El guardián del olvido (1990) y El misterio de la mujer autómata (1991) de Joan Manuel Gisbert; El maestro y el robot (1983) de José Antonio del Cañizo; Los batautos hacen batautadas (1981), Los batautos en Butibato (1986), El secreto de la flauta de piedra (1989) de Fernando Alonso; Regreso a Un lugar llamado Tierra (1986) de Jordi Sierra i Fabra; La ciudad de la lluvia (1984) de Juan Carlos Eguillor; La ciudad que tenía de todo (1985) de Alfredo Gómez Cerdá; El caballo fantástico (1985) de Moisés Ruano y El temible Safrech (1992) de Ricardo Alcántara. Estas obras exploran de diversos modos la imaginación, parten de situaciones reales o históricas como la guerra, el mundo de los negocios, la tecnología, la vida en la escuela, la contaminación, el abandono de la niñez; denuncian vicios o costumbres sociales como la pereza, aprovechan el humor y juegan con las jerarquías establecidas por y para los adultos. Tienen la importancia de rescatar la fantasía y el poder de la imaginación como un atributo esencial de todo ser humano, que le lleva a interrogarse sobre su existencia y su mundo y también le enseña a valorar los mitos y la tradición cultural.

Las obras realistas tratan problemas concretos, hechos históricos o la descripción del acontecer cotidiano de una familia o población, para construir una imagen crítica de la sociedad. Con respecto a lo ocurrido en las tres primeras décadas de la posguerra, los autores se muestran agresivos e innovadores en los temas que emplean. Se deja al margen la visión de una sociedad unitaria y armónica y se presentan muchos de los cambios sociales que están ocurriendo y que dan paso a temas que tradicionalmente habían permanecido en silencio como la locura, la incomunicación, la muerte, el desamor, etc. Es aquí donde el realismo adquiere su sentido. Éste, y más concretamente, el realismo crítico, intenta presentar al lector la problemática social y humana que lo rodea, de manera que se convenza de que el único camino para superarla es mediante una toma de conciencia sobre ella. Este es el primer paso para lograr una verdadera transformación social desde la literatura. A pesar de que el realismo crítico tuvo su auge, no trascendió porque anteponía intereses ideológicos al trabajo artístico. Esto ocurrió en general con la narrativa española y no solo en la infantil.

La historia, la crítica social, los problemas familiares y el amor adolescente son, a criterio de Amalia Bermejo (1999: 32), los temas abordados con más claridad en el realismo. Para ella, el escritor logra superar el costumbrismo ingenuo que presentaba hechos y situaciones diarios con un tono trivial. Aparece así una narrativa que examina la realidad de una manera seria y crítica, utilizando los recursos retóricos adecuados para tal fin.

Muchos temas nacionales y ámbitos de la realidad personal y cotidiana son representados con la mirada profunda de autores que buscan transmitir al niño una imagen lo más fiel posible de la realidad. Por ello, cobran mucha importancia las novelas de aprendizaje como La gripe de Buffalo Bill (1981) de Francisco Climent, Piedra de toque (1983) de Montserrat del Amo, Un monstruo en el armario (1991) de Carmen Vázquez Vigo, etc.; obras con un trasfondo histórico como Las lágrimas del sol (1981) de José María Merino, Cuerpos de cobre, corazones de jade (1990) de Juana Aurora Mayoral, Paso a la Reina Isabel (1990) de María 
Dolores Pérez Lucas, entre otras; obras de denuncia social como Una familia casi normal (1988) de Pablo Barrena y Los mercaderes del diablo (1989) de Juan Farias; obras que presentan críticamente el mundo familiar como Los trapos sucios (1997) de Elvira Lindo, etc.

Junto a estos temas, los autores también se preocupan por otros como la Guerra Civil, la transformación de la sociedad rural, la descripción del mundo urbano y la reivindicación de nuevos valores, los cuales son recurrentes y revelan una toma de conciencia de los escritores respecto del entorno social, así como un gran esfuerzo en cuanto a los recursos y técnicas, para insertarlos en el mundo ficticio.

La trilogía Crónicas de Media Tarde de Juan Farias, compuesta por Años Difíciles, El barco de los peregrinos y El guardián del silencio, así como Los pequeños nazis del 43 (1987) del mismo autor, abordan de un modo particular la temática de la guerra, una temática poco evocada en España, lo cual parece responder a una clara voluntad de olvido de ella (Colomer 1990: 146). Además, obras como El viaje en el jardín (1986) de Jesús Fernández, Hubo una vez otra guerra (1988) de Luis A. Puente y Fernando Lalana, etc., conforman una imagen más amplia y problemática de los modos en que ha sido percibida la guerra en la literatura infantil y juvenil española.

En lo referente a la imagen de la sociedad rural que se proyecta en la narrativa infantil y juvenil española de la época, esta es prácticamente de desolación y decadencia. Los textos $E l$ amigo oculto y los espíritus de la tarde (1984) de Concha López Narváez, Soñado mar (1981) de Montserrat del Amo, El cuento interrumpido (1983) de Pilar Mateos, El guardián del silencio (1985) de Juan Farias, y La puerta (1989) de Rodrigo Rubio, son las obras más representativas de esta tendencia. Estas obras también aluden, de diversos modos, al acelerado proceso de urbanización que ha tenido España y a la reducción del campo al recuerdo y la melancolía de las generaciones anteriores. Por otra parte, la vida urbana se ha convertido en uno de los principales núcleos temáticos, como se aprecia en Jeruso quiere ser gente (1981) de Pilar Mateos, Una familia casi normal (1988) de Pablo Barrena, y en Ramuntxo detective (1989) de Bernardo Atxaga.

Además, la literatura infantil y juvenil realista que se produce en toda España es una literatura que plantea una lucha contra todo tipo de discriminación y prejuicios, y se presenta con una gran actualidad, abordando temas del contexto inmediato, como ocurre con aquella literatura que trata sobre los problemas ecológicos. Algunas de las obras que sobresalen son La comilleta Marcella (1980) de Ester Tusquets, El río de los castores (1981) de Fernando Martínez Gil y Las otras minas del Rey Salomón (1985) de Francisco Climent, La isla de Jacobo (1990) de Juan Farias, entre otras. Estas son obras que plantean la relación entre el ser humano y el medio ambiente y hacen conciencia sobre dicho asunto, pero no por ello deben analizarse únicamente en función de este objetivo.

Aunque no se puede negar que haya predominado el realismo, sobre todo a partir de 1985, como ha afirmado Caterina Valriu (1994: 42) al colocar la novela realista como el 'género estrella', la narrativa fantástica ha tenido un notable desarrollo. Si bien las obras realistas apelan al niño para que reflexione sobre la realidad histórica, esto también aparece en la narrativa fantástica, la cual obedece a un proyecto definido de los autores. Algunos narradores se inclinan por una determinada tendencia, pero también se presentan obras que logran una excelente síntesis de ambas, como por ejemplo El maestro y el robot (1983) de José Antonio del Cañizo y Memorias de una vaca (1992) de Bernardo Atxaga, en las cuales la realidad y la fantasía no se excluyen; por el contrario, se complementan. 
Asimismo, la presencia y relación de la realidad y la fantasía en las obras literarias no es un asunto totalmente novedoso, pues en los libros de diversos autores de las décadas previas a la guerra ya aparecían combinadas de un modo extraordinario. Lo que cambia es el contexto y la intencionalidad de su utilización. En los primeros años de la posguerra, se eludía la realidad concreta y, quizá sin llegar a temas puramente fantásticos, los niños leían apologías de los "héroes" españoles o historias lejanas a su realidad. Pero desde los años sesenta se abre camino a una narrativa realista que busca enfrentar al niño a su contexto y cuando irrumpe la fantasía es para ampliarle el mundo que se le está ofreciendo. No necesariamente para abstraerlo de su realidad concreta, porque muchos de los libros que se ubican dentro de la fantasía parten de la realidad misma y pretenden hacer conciencia sobre ella, tanto como las mismas obras realistas. Aún así, hay críticos que opinan que la fantasía ha sido empleada como tema para responder a ciertas demandas pedagógicas (Colomer 1998: 123) olvidando de alguna manera que el universo infantil (y el del adulto también) es una mezcla indefinible de realidad y fantasía.

\subsection{La diversidad temática y las innovaciones formales}

La narrativa que se produjo durante el periodo franquista se caracterizó fundamentalmente por el privilegio de unos determinados temas que correspondían a los intereses dominantes. Eran temas fundamentalmente históricos y religiosos que buscaban construir una imagen positiva de la sociedad española, pero que no revelaban el verdadero sentir de los españoles y también limitaban las posibilidades expresivas. Transmitían la idea de una sociedad grandiosa pero estática, con una retórica poco dinámica, pues casi siempre se empleaban los mismos recursos retóricos. En el periodo democrático, la situación cambia totalmente: la narrativa se abre a los más variados temas y representa de un modo más amplio las transformaciones sociales y los gustos culturales. Para ello, los autores recurren a técnicas capaces de sensibilizar a los niños en relación con su entorno y de expresar su imaginación y fantasía.

Esta renovación temática y formal se vincula también a la desaparición de la censura en el nivel oficial, si bien en el ámbito personal, institucional y editorial se mantiene de distintas maneras. Fernando Cendán Pazos (1986: 63) se refiere a la importancia capital que adquiere la Constitución Española de 1978, en cuanto a la supresión de la censura Este hecho, además de contribuir con la transformación histórica y política de España, ha propiciado las condiciones fundamentales para el desarrollo cultural y literario. Textualmente, la Constitución española de 1978 en el Título Primero (De los derechos y deberes fundamentales), Capítulo II (Derechos y Libertades), Sección 1 (De los derechos fundamentales y de las libertades públicas), Artículo 20, dice:

\footnotetext{
1. Se reconocen y protegen los derechos:

A expresar y difundir libremente los pensamientos, ideas y opiniones mediante la palabra, el escrito o cualquier otro medio de reproducción.

A la producción y creación literaria, artística, científica y técnica.

A la libertad de cátedra.

A comunicar o recibir libremente información veraz por cualquier medio de difusión. La ley regulará el derecho a la cláusula de conciencia y al secreto profesional en el ejercicio de estas libertades.

2. El ejercicio de estos derechos no puede restringirse mediante ningún tipo de censura previa ${ }^{18}$.
} 
La actividad literaria toma mayor fuerza y no existe limitación expresa para tratar cualquier tema. José María Martínez Cachero (1985: 379), refiriéndose en general a toda la narrativa española, apunta que "desaparece, sí, la censura, atenuada en los últimos años del franquismo, y a partir de su desaparición todos los temas y posibles tratamientos serán legítimos y posibles" Este hecho acaba con las barreras ideológicas para los escritores, quienes pueden aprovechar la libertad que ahora tienen, siempre en función de la calidad artística. De alguna manera, esto se constituye en un nuevo reto para ellos.

A partir de los años setenta, los autores de narrativa infantil orientan sus obras hacia diferentes temáticas. Son conscientes de su trabajo de escritura y producen textos de acuerdo con sus preferencias: unos más cercanos a la fantasía; otros, al realismo. Se preocupan por recuperar en forma amplia el mundo infantil; de ahí que utilicen diversidad de temas ${ }^{19}$ y que no se restrinjan a ciertos parámetros ideológicos externos:

Los últimos años han conocido nuevos rasgos en tales temas, al orientarse hacia una problemática más concienciadora ante los conflictos personales, en una visión desprovista de ciertos tópicos y preocupada por la defensa de la peculiar visión infantil sobre determinadas realidades (García Padrino1992: 552).

Por ello, surgen textos que tocan distintos temas (como la novela iniciática o bildungsroman $^{20}$ ) y otros que abordan temas históricos, ecológicos, familiares, sociales, fantásticos, psicológicos, etcétera. A pesar de que varios autores desarrollen un mismo tema, generalmente el enfoque resulta particular y diferente y las innovaciones formales permiten distinguir claramente el aporte de cada uno de ellos. Además, se incorporan aquellos temas que tradicionalmente habían sido considerados como tabú o simplemente conflictivos: la muerte, el racismo, la injusticia social, la guerra, la crueldad, la incomunicación, el sexismo, la contaminación, la anorexia, el suicidio, la depresión, etc. Lo importante es que estos temas son tratados con una concepción artística, libre de elementos que pretenden moralizar (Hendriks 1990: 14) y, por lo tanto, puesta únicamente al servicio de la naturaleza literaria de las obras.

Hay una clara renovación temática que implica de por sí una renovación de los valores y de los modelos sociales de los que se había nutrido la narrativa anterior. La sociedad ha ido cambiando sustancialmente y, con ella, los valores y sistemas morales. El niño se enfrenta a una realidad múltiple y plural, con nuevas concepciones de la familia, del sexo, la religión, la realidad política, la cultura, etc., lo cual afecta de dos maneras a la literatura que se produce. Por un lado, muestra un panorama muy diverso y enriquecedor y, por otro, plantea la dificultad de encontrar una visión homogénea de la sociedad. Así, podría pensarse que la diversidad temática también es resultado de una nueva sociedad en la que funcionan múltiples discursos relacionados con el mundo infantil.

La diversidad temática ha llevado al desarrollo de importantes modalidades genéricas como la novela iniciática, la psicoliteratura ${ }^{21}$, las obras de denuncia social, la novela ecologista, la novela sobre la guerra, la novela fantástica, etc. Todas estas modalidades han tenido un éxito importante en el público lector, algunas favorecidas por el apoyo que han recibido del sector educativo, como es el caso de la psicoliteratura.

Los cambios en la temática también han repercutido en las técnicas narrativas y, en general, en el plano de la expresión. La diversidad de intereses y los múltiples temas tratados (a lo cual se suma la gran cantidad de autores y obras que han emergido) han conducido a la experimentación y a la exploración de nuevos modos narrativos. Los autores, en su afán de 
ruptura y originalidad, pretenden estar a la vanguardia y esto los ha obligado a ser cada vez más creativos. Pero, en general, la gran vitalidad y el dinamismo que ha cobrado la narrativa infantil y juvenil en este periodo debe mucho a que los autores han sabido asumir distintas ópticas para el tratamiento de los temas y han concedido a la forma y a la retórica un valor primordial. Si bien los temas resultan trascendentes, la materialidad lingüística, la experimentación, el juego y la combinación especial de recursos retóricos producen unos determinados efectos estéticos que contribuyen a la renovación del género.

Teresa Colomer (1990: 151) sostiene que la narrativa de este periodo busca un lenguaje verosímil y muy cercano al receptor, y se preocupa por

\footnotetext{
...la sobriedad, la condensación narrativa, de tal forma que la transmisión de la vivencia se plantea a través de una cuidadosa selección de detalles cotidianos que el lector puede percibir como propios de su experiencia y que se encargan de resumir de forma intensa la descripción del conflicto.
}

En todo momento, los autores procuran incorporar al niño a la ficción y por ello parten de elementos o hechos que les resultan familiares. El mundo creado es consecuente con la realidad o las posibles experiencias del protagonista, pero para generar esa sensación se hace necesaria una selección muy adecuada de los asuntos por narrar, así como el empleo de aquellas técnicas que hagan posible la mayor expresividad lingüística.

Los recursos retóricos utilizados son variados y múltiples según el tipo de relato, la naturaleza genérica de las obras y el modo de enunciar los temas. En general, en muchas obras se observa un predominio del humor, la intriga, el suspenso, el humor negro, la ironía, distintas perspectivas narrativas, los diálogos, los juegos temporales, etc. Sobre estos últimos, Victoria Sotomayor Sáez (2000: 33) analiza las variantes en la ordenación temporal y se refiere particularmente al recurso de la ambigüedad temporal y el alejamiento simbólico del presente, en relatos como El castillo de las tres murallas (1981) de Carmen Martín Gaite, El verdadero final de la bella durmiente (1995) de Ana María Matute y a la anulación del tiempo en "La larga siesta del papá", narración que aparece en Algunos niños, tres perros y más cosas (1981) de Juan Farias, en la que se funden pasado y presente.

Los cambios que se presentan obedecen al propósito de muchos escritores de abordar el mundo del niño desde los más variados ángulos, lo que introduce importantes cambios en la voz narrativa. El narrador omnisciente es generalmente sustituido por un narrador en primera persona y se aprovechan al máximo las posibilidades expresivas que tienen las formas dialogadas. Con ellas, la narración cobra más vida y transmite de un modo más directo el mundo infantil, en todas sus dimensiones. Las variaciones en la forma, la alternancia en las voces narrativas, la combinación de focalizaciones, la presencia de distintos tipos de narrador y narratarios, se convierten, según Victoria Sotomayor (40), en artificios que no solo validan el carácter literario de una obra sino que contribuyen a desarrollar la competencia literaria del lector.

El humor constituye una de las características centrales de la narrativa infantil posterior al restablecimiento de la democracia. El distanciamiento que se logra con su empleo entre el autor y el mundo narrado impregna la narración de objetividad. Este recurso permite el tratamiento de temas y conflictos de modo que genera diversión y reflexión en el receptor infantil. Para Colomer (152-3),

El género humorístico iniciará su despegue en los años setenta a tenor de las nuevas actitudes ideológicas 
que incluyen la admisión de la transgresión de la norma moral en los niños, la potenciación del juego como exploración de los códigos de convivencia, la búsqueda de los cauces para la liberación de las pulsiones infantiles y una actitud vitalista ante la acentuación de la pluralidad de discursos sociales.

A partir de los ochenta surge una interesante producción de obras humorísticas como es el caso de Las fantásticas aventuras del Caballito Gordo (1980) de José Antonio del Cañizo, El pirata Garrapata (1982) de Juan Muñoz Martín, Marcelo crecepelos (1983) de Fernando Almena, Libro del voliches, laquidamios y otras especies (1986) de David Civici. En un sentido más estricto, hay obras que muestran una tendencia transgresora y provocadora, y junto al humor incorporan también el terror, el absurdo o la ciencia ficción, como puede notarse en las obras Mercedes e Inés o cuando la tierra da vueltas al revés (1981) de Consuelo Armijo y El maestro y el robot (1983) de José Antonio del Cañizo.

La experimentación formal tiene su fundamento en la necesidad de expresar, con la mayor originalidad posible, una realidad heterogénea y compleja. El juego con las reglas de construcción literaria se impone y afloran diversos recursos como la ironía, la ambigüedad, el equívoco, etc., los cuales marcan un importante cambio con los sistemas narrativos y con las formas convencionales de expresar la realidad. Se impone la voluntad de transmitir una realidad plurisignificativa y se asume una concepción de la obra literaria como un "juego compartido entre emisor y receptor" (154), un artificio producto de la interacción de ambos y que genera nuevos enfoques de la realidad y muestra las variadas posibilidades significativas de la lengua. Solo como ejemplo de ese juego entre emisor y receptor, véanse las obras Datrebil, siete cuentos y un espejo (1982) de Miquel Obiols y Los caminos de la luna (1997) de Juan Farias, las cuales integran plenamente al lector en el juego y la dinámica que implican los textos.

Se incorpora, además, la experimentación formal de la vanguardia del siglo XX, tomando como referencia la obra del italiano Gianni Rodari, que de alguna manera representa también una reacción de los escritores ante el realismo dominante en el momento. En el espacio textual, se generan asociaciones insólitas, fragmentación de secuencias, historias solo insinuadas y, en general, variedad de rupturas imaginativas que modifican la lógica narrativa. En síntesis, se presenta una clara conciencia de transgredir la narrativa tradicional y de crear una literatura donde el humor, la ironía y la fantasía adquieren un rango preponderante. Las obras de Pilar Mateos, Consuelo Armijo, Juan Farias, José Antonio del Cañizo, Miquel Obiols, Joles Sennel, entre otros, ilustran esta significativa transformación. Por otra parte, Joan Manuel Gisbert explora ampliamente una vertiente fantástica en la que se personifica la naturaleza, se retoman la mitología y la magia con el fin de crear imágenes integradas en esquemas de aventuras y suspenso.

También han cobrado relevancia, nuevamente, géneros narrativos como el policiaco y la ciencia ficción, que incluso han llevado a las editoriales a crear series para ellos. Son géneros que representan el afán de experimentación de los escritores. La obra Ramuntxo detective (1980) de Bernardo Atxaga se ubica dentro del primero; El maestro y el robot (1983) de José Antonio del Cañizo y la trilogía de Jordi Sierra Regreso a Un lugar llamado Tierra (1986), El testamento de Un lugar llamado Tierra (1986) y En Un lugar llamado Tierra (1987) se ubican dentro de la ciencia ficción. El género policiaco le permite a los autores plantear, mediante un juego experimental, las peripecias que deben enfrentar los protagonistas para resolver los múltiples enigmas que encuentran en las obras, mientras que la ciencia ficción les brinda la posibilidad de emplear escenarios y personajes exóticos como robots o extraterrestres.

En cuanto a los recursos expresivos utilizados, Teresa Colomer (1999: 136) destaca 
los siguientes aspectos: a) la narración psicológica, que es una de las tendencias con mayor éxito editorial en la actualidad y que se caracteriza por el uso simbólico de la fantasía, las ambigüedades y la distancia humorística; b) renovación de la fantasía, uso de distintas formas de desmitificación y subversión, empleo de escenarios folclóricos, de juegos surrealistas y c) utilización de recursos de la posmodernidad, como la ruptura de la lectura inocente (empleo de lector cómplice), la parodia, la intertextualidad, la fragmentación y la mezcla de distintos códigos. Algunas obras en las que se observa el uso consciente de estos recursos expresivos son: La guía fantástica (1977) y El bosque encantado (1982) de Joles Sennell; Datrebil, 7 cuentos y un espejo (1982) de Miquel Obiols; Ala de mosca (1989) de Asun Balzola; El guardián del olvido (1990) de Juan Manuel Gisbert; Caperucita en Manhattan (1991) de Carmen Martín Gaite; Memorias de una vaca (1992) de Bernardo Atxaga; Han quemado el mar (1993) de Gabriel Janer Manila; Los caminos de la luna (1997) de Juan Farias y Día de Reyes Magos (1999) de Emilio Pascual.

Los autores asumen la obra literaria como un artificio en el que es posible la experimentación y también la transmisión de la complejidad de un mundo que cada día parece más ambiguo y escindido. La funcionalidad del lenguaje es tomada como asunto prioritario que se sobrepone a cualquier tema y el lector se siente exigido a participar en la ficción, entrando en un juego para descodificar y reconstruir la realidad. En este sentido, se produce una narrativa que comparte las preocupaciones del mundo contemporáneo y, por tanto, de los autores que se dirigen a los adultos, con la especificidad de que su centro de interés es el mundo infantil.

\section{A manera de conclusión: un panorama diverso y complejo}

La narrativa infantil enfrenta, desde el restablecimiento de la democracia, dos grandes dificultades para alcanzar un desarrollo pleno, tal y como lo ha apuntado Jaime García Padrino (1992: 536) al referirse a la explosión editorial y la simbiosis entre el libro infantil y el libro escolar, derivada de la reforma que se inició en 1970 con la Ley General de Educación. Por una parte, hay una avalancha de publicaciones producto de la aparición de más editoriales y de una política más agresiva por ocupar el mercado del libro infantil; por otra, se procura que el libro responda a ciertos fines didácticos, e incluso en muchos de ellos aparecen guías de lectura. Esto obviamente no favorece la imaginación y el poder evocativo de los textos literarios, porque reduce y limita el potencial significativo.

La multitud de publicaciones señalada en el párrafo anterior también trae serias dificultades para discernir cuáles son los textos que verdaderamente están contribuyendo a la conformación de la narrativa infantil actual. Múltiples editoriales ponen gran empeño en crear series y colecciones, y la edición formal resulta de muy alta calidad, pero no siempre esta responde al valor artístico de las obras. La Editorial Espasa Calpe en su colección Austral Juvenil se propone publicar la obra de los autores más representativos de las nuevas tendencias de la literatura infantil; Ediciones Lóguez $^{22}$ se encarga de publicar aquella literatura infantil contemporánea más comprometida en sus contenidos sociales; la Editorial S. M., en su colección Barco de vapor, incluye obras destinadas fundamentalmente al rescate de valores y por ello se dirige a un público amplio constituido por el niño como destinatario principal, padres, educadores y bibliotecarios.

El crecimiento del mercado del libro infantil y juvenil muy pronto incidió en la cali- 
dad de las obras. La demanda aumentó y las editoriales se vieron obligadas a ofrecer a los lectores diversos libros de autores consagrados, jóvenes y también traducciones de los autores europeos de la época. Ana Garralón (2000: 29) señala que la avidez de las editoriales ha perjudicado notablemente a la literatura infantil y juvenil, ya que incluso han ejercido presión sobre los escritores más destacados para que publiquen libros de menor calidad.

Ante esta diversidad, y a falta de elementos críticos que contribuyan a discernir sobre la calidad de las obras, Jaime García Padrino, en su estudio "Clásicos de la literatura infantil española" (2000), con base en criterios históricos, estéticos y de representatividad, ofrece una lista de obras que pueden considerarse modélicas, la cual es producto de su lectura de una gran cantidad de obras que se han publicado y que no habían sido evaluadas con propiedad. Con las limitaciones que tiene esta lista ${ }^{23}$, resuelve una necesidad urgente y otorga a críticos, maestros, bibliotecarios y lectores en general, una orientación para discernir sobre las obras más sobresalientes.

Aparte de las dos dificultades señaladas, se puede concluir que el periodo anterior a 1975 estuvo dominado por elementos ajenos a la especificidad literaria que condicionaron el tipo de literatura infantil que se produjo en España; sin embargo, no se puede negar que en dicho periodo se realizaron importantes esfuerzos para renovar la literatura infantil y asumir la imagen del niño como el principal centro de interés. Autores como José María Sánchez Silva, Ángela Ionescu, Carmen Kurtz, entre otros, supieron crear una literatura suficientemente imaginativa como para superar y trascender la censura impuesta por el régimen político imperante.

En los años posteriores al franquismo, se produjo un cambio fundamental: se retomaron los esfuerzos renovadores y se gestó una literatura muy diversa. Se han presentado proyectos muy serios que dan a la literatura infantil un espacio realmente significativo en el campo cultural y literario. Los autores, con un espíritu amplio y abierto, han abordado el mundo infantil desde los más variados ángulos, siempre con el afán de concederle un protagonismo en el universo narrativo. Ello les ha obligado a incorporar innovaciones formales y temáticas que muestran un panorama muy particular. No existen grandes tendencias homogéneas y más bien domina la heterogeneidad. Se da una clara apertura hacia las tendencias que estén en boga en otros países europeos y se genera un constante diálogo con ellas.

La influencia de los autores europeos demuestra las inquietudes que los españoles han tenido por participar de una renovación constante. La narrativa fantástica de Gianni Rodari, la novela psicológica de María Gripe, el nonsense, el realismo crítico y el humor al estilo de Roald Dahl, son claros ejemplos de cómo se incorporan las nuevas tendencias europeas a la narrativa infantil española.

Como ejemplo del valor que se le sigue concediendo a esta integración a la literatura europea, Gabriel Janer Manila, en el congreso titulado "La literatura infantil i la construcció d'Europa", organizado por el Institut d'Estudis Baleàris, en 1995, hacía ver la necesidad y conveniencia de fortalecer los nexos existentes y crear otros nuevos, con el fin de que haya una verdadera interacción entre estas literaturas:

És evident que dels objetivs d'aquestes IV Jornades del Libre Infantil i Juvenil en llengua catalana és participer en l'elaboració d'un discurs que consolidi la imatge de la nostra literatura infantil en l'ambit cultural europeu. Una literatura plena de vitalitat, que necessita, en el tambont de segle, la interconnexió amb altres experiències i altres pisos. Una interconexió en perfecta harmonia ${ }^{24}$.

El cambio de la dictadura al sistema democrático no ha sido garantía para un verdadero desarrollo de la narrativa infantil. Así como puede hablarse de un salto cualitativo, no se 
debe desconocer el hecho de que no todo lo publicado reúne las condiciones artísticas para una mayor proyección. Incluso, hay estudiosos que formulan juicios muy radicales, como lo hacen Caterina Valriu y Pablo Barrena, quienes adoptan una posición muy crítica con respecto a la gran cantidad de narrativa infantil que se ha producido en los últimos años y hasta llegan a afirmar que muchos autores se arriesgan poco a la hora de crear, repiten fórmulas tomadas de otros escritores y, por lo tanto, las innovaciones que se hallan en el nivel estilístico son escasas (Barrena 1999: 11 y Valriu 1994: 44). La opinión de Barrena es quizá la más crítica, pues señala que en los noventa se imponen temáticas abiertas pero planas, las construcciones narrativas son cada vez más sencillas, hay repetición y fugacidad, se acentúa el predominio de lo educativo y no se fomenta el desarrollo de la inteligencia.

También Ana Garralón (2000: 36) ofrece un panorama desalentador. Compara la década de los ochenta con lo sucedido en los noventa y observa notables diferencias. La primera se caracteriza por la existencia de creaciones desbordantes y atrevidas, tanto en la retórica como en los temas, pero en los noventa empieza un lento declinar y se entra en una crisis seria donde predomina la mediocridad, la uniformidad y la rapidez. Reconoce que hay obras sobresalientes, pero no encuentra autores con una producción verdaderamente extraordinaria.

Merece la pena detenerse a analizar los juicios de estos críticos, a la luz de lo que aportan las obras; ellos se refieren al panorama general y no sustentan sus afirmaciones con ejemplos tomados de los textos. En definitiva, el examen detallado de las obras proporciona los criterios necesarios para una valoración más real de la narrativa que se ha producido; de ahí la pertinencia de efectuar investigaciones orientadas a la consecución de este fin.

\section{Notas}

1. La complejidad no solo se restringe al plano lingüístico y estético de los textos, sino también al hecho de que hay regiones con un idioma diferente y con proyectos culturales particulares. Se publica tanto en castellano como en catalán, vasco y gallego. A esto se le agrega también la existencia de editoriales, premios y otras actividades que si bien se enmarcan dentro del desarrollo general de la literatura española, responden muchas veces a intereses nacionalistas. Por otra parte, los autores más destacados que han publicado en catalán, vasco y gallego, también han sido traducidos al castellano, lo cual de alguna manera permite observar, sin dejar de considerar las diferencias, cuáles son los autores más representativos de la actual literatura infantil española. En todo caso, merece la pena un estudio que permita establecer las relaciones existentes en el campo de la literatura infantil entre las diversas zonas y lenguas de España, sin negar el aporte de algunos trabajos que existen al respecto, como por ejemplo, 28 libros da literatura infantil e xuvenil galega (1988) de Agustín Fernández, La literatura infantil vasca (1988) de Seve Calleja y Xabier Monasterio, Autores galegos de literatura infantil (1989) de Xulio Cobas, Història de la literatura infantil i juvenil catalana (1994) de Caterina Valriu.

2. Es importante aquí retomar, en lo referente al teatro, la opinión de María Hendriks, quien sostiene que la labor de investigación y creación de autores como Juan Cervera, Luis Matilla, Josep María Benet, Alfredo Mantovani, entre otros, refleja la seriedad con que se está trabajando en este género. Ella destaca que estos autores se han preocupado mucho por la incorporación activa del niño al juego dramático, por hacerlo creador y animador y además por darle un tono crítico y reflexivo a sus obras. Véase Hendriks, María (1990: 43). No obstante, no debe olvidarse que las actividades teatrales generalmente han sido financiadas por iniciativas del sector privado y no se han limitado exclusivamente a piezas españolas. 
3. Véanse los textos Poesía infantil. Teoría, crítica e investigación (1990), de Pedro Cerrillo y Jaime García Padrino (Coordinadores); Historia crítica del teatro infantil español (1982) de Juan Cervera; Dramatización y teatro infantil (1994) de Isabel Tejerina. "Teatro infantil en España: rasgos y obras representativas". En: Primeras noticias, núm.150 (1997) de Isabel Tejerina y "Lenguaje literario, géneros y literatura infantil” de Victoria Sotomayor Sáez. En: Presente y futuro de la literatura infantil (2000).

4. Jaime García Padrino (1992: 398) considera que esta labor no ha tenido una verdadera continuidad en los años posteriores.

5. Ibid., p. 399. En otro trabajo, publicado en 1987 (114), Jaime García Padrino afirmó que la Guerra Civil Española había cercenado de raíz dicho panorama alentador.

6. España. 1996. Constituciones españolas. Madrid: Imprenta Nacional del Boletín Oficial del Estado, p. 322. El espíritu de este artículo se retoma y amplía en el artículo 20 de la Constitución Española de 1978.

7. Véase el libro Elena Fortún (1886-1952). Madrid: Asociación Española de Amigos del IBBY. 1986, p. 27.

8. Véase además Dorao, Marisol. 1999. Los mil sueños de Elena Fortún. Cádiz: Universidad de Cádiz. En el capítulo 8, la autora amplía lo señalado por García Padrino, al afirmar que los cuentos y artículos publicados por Elena Fortún en dicha Revista, así como la obra Celia en la revolución (1987), descubren las penurias y limitaciones materiales provocadas por los enfrentamientos bélicos. Fortún cuestiona, además, la actitud irracional de los hombres al provocar la guerra.

9. Entre los escritores que debieron exiliarse están Elena Fortún, Antoniorrobles y Juan Ramón Jiménez. En un ámbito más amplio, Félix Santos ha calificado las consecuencias del exilio como una mutilación cultural. Véase: Santos, Félix. 1999. Exiliados y emigrados. Madrid: Fundación Españoles en el Mundo, p. 25.

10. A pesar del contexto ideológico en que se produce la obra de José María Sánchez Silva, el aporte de este autor a la literatura infantil española es capital. Recuérdese que es el único español que ha recibido el Premio Hans Christian Andersen, en 1968.

11. Cuando el libro iba a ser editado, el clérigo que asesoraba al editor Afrodisio Aguado, lo leyó y expresó que el libro atentaba contra la fe católica, por lo cual se rechazó. Véase el apéndice preparado por Emilio Pascual a la edición de Marcelino, pan y vino. 1985. Madrid: Anaya, p. 209.

12. Es importante mencionar aquí que este libro recopila textos de autores que eran niños en el periodo de la guerra y que publicaron sobre este tema en la década de los setenta y principios de los ochenta. Por ejemplo, Jesús Fernández Santos ("El primo Rafael”), Carmen Martín Gaite ("El cuarto de otras"), Rafael Azcona ("Casette"), Juan Benet (Así era entonces, Cuentos completos), Juan García Hortelano ("Carne de chocolate"), Medardo Fraile ("Retrato ejemplaria”), Ana María Matute (Cuaderno para cuentos, Algunos muchachos) e Ignacio Aldecoa (Patio de Armas).

13. En realidad, la adopción de comportamientos clichés no es exclusiva del periodo franquista ni de España, pues en el siglo XIX y la primera mitad del siglo XX, existió una tendencia a crear ejes estereotipados en los que los niños se desenvuelven en un maniqueísmo, entre buenos y malos. Véase Gómez del Manzano, Mercedes. 1987. El protagonista niño en la literatura infantil del Siglo XX. Madrid: Narcea, p. 63.

14. Para una visión más amplia y clara de la labor editorial durante el periodo 1950-1970, véanse las páginas 517-22 de este mismo libro.

15. En su libro La formación del lector literario (1998), p. 56, Teresa Colomer retoma la contribución de Bruno Bettelheim, quien ha resaltado la función transformadora de la vida interior que tiene la literatura 
fantástica.

16. El "non-sense" puede traducirse como "sin sentido" y es un tipo de creación de origen británico. Es una mezcla de fantasía y humor, en un tono disparatado. Véase: "Un libro al mes... bien poco es". En: Platero, núm. 91, 1997, p. 5.

17. En el campo de las novelas de aventuras puede incluirse también la llamada novela negra, la cual tiene un carácter policiaco pero se define ante todo por la trama, que consiste en el esclarecimiento de un enigma, y porque utiliza un lenguaje coloquial, describe los bajos fondos y en general los ambientes marginales, se basa en móviles económicos o pasionales y tiene un ritmo muy intenso.

18. España, Ob. cit., p. 351.

19. Para observar en detalle la diversidad de temas tratados consúltese "La literatura infantil y juvenil en España (1939-1990)" de Teresa Colomer, Libros y literatura para niños en la España contemporánea de Jaime García Padrino y Corrientes actuales de la narrativa infantil y juvenil española en lengua castellana de Cubells et al. Estos críticos agrupan varias obras por temas, con un fin ilustrativo y práctico más que clasificador.

20. La novela iniciática o bildungsroman está estrechamente relacionada con la psicoliteratura. Parte de una inmadurez como tema inicial y avanza hacia un desarrollo pleno del personaje. Véase: "Un libro al mes... bien poco es". En: Platero, núm. 91. 1997, p. 5.

21. A la psicoliteratura también se le ha llamado libro psicológico, relato intrasíquico, novela psicológica, novela pedagógica; desarrolla como aspecto fundamental el conflicto interior de los personajes, adolescentes que se ven afectados por los cambios que han sufrido sus vidas, cambios relacionados con la personalidad y la estructura familiar, como el divorcio de los padres, por ejemplo. Véase: Lage Fernández, Juan José. 1992. "La psicoliteratura o libros de familia”. En: Cuadernos de Literatura Infantil y Juvenil. Barcelona: Fontalba, núm. 69, pp. 52-58; Lage Fernández, Juan José. 1995. "Psicoliteratura y libros de familia”. En: Cuadernos de Literatura Infantil y Juvenil. Barcelona: Fontalba, núm. 69, pp. 27-36, y Lluch Crespo, Gemma. 1996. "La literatura de adolescentes: la psicoliteratura”. En: Didáctica de la lengua y la literatura, Barcelona, núm. 9, pp. 21-28.

22. Para un panorama completo del trabajo desempeñado por las editoriales a partir de los años setenta, véase a García Padrino, Jaime 1992: pp. 539-45.

23. El mismo autor reconoce las dos principales limitaciones: se trata de un canon de elaboración personal y está centrado en la literatura infantil en lengua castellana.

24. Véase la Introducción al libro La literatura infantil i la construcció d'Europa. Estudios Baleàricos. núm. 52. Palma de Mallorca, España, 1995, preparada por Gabriel Janer Manila.

\section{Bibliografía}

Albanell, Josep. 1990. "Relástico fantismo”. En: Cubells et al., 25-9.

Barrena, Pablo. 1988. "Una oferta que va en aumento pero que aún resulta escasa y desigual”. Alacena. Madrid, núm. 7. 1999. "La literatura infantil y juvenil de los años noventa ante el futuro". Ponencia 
presentada en $7^{\circ}$ Jornadas de Bibliotecas Infantiles y Escolares: Literatura para cambiar el siglo. Salamanca: Fundación Germán Sánchez Ruipérez.

Bermejo, Amalia. 1999. La literatura infantil en España. Madrid: Asociación Española de Amigos de Libro Infantil y Juvenil.

Cañizo, José Antonio del. 1990. "Non sense o superrealismo infantil”. En: Cubells et al., 31-5.

Cendán Pasos, Fernando. 1986. Medio siglo de libros infantiles y juveniles en España (19351985). Madrid: Pirámide/Fundación Germán Sánchez Ruipérez.

Cerrillo, Pedro y Jaime García Padrino (Coords.). 2000. Presente y futuro de la literatura infantil. Cuenca: Ediciones de la Universidad de Castilla - La Mancha.

Chapa Eulate, Victoria. 2000. "Presente y futuro de la literatura infantil". En: Cerrillo, Pedro y Jaime García Padrino (Coords.), 101-9.

Colomer, Teresa. 1990. “La literatura infantil y juvenil en España (1939-1990)”. En: Nobile, Angelo.

1991. "Últimos años de la literatura infantil y juvenil". Cuadernos de Literatura Infantil y Juvenil. Núm. 26: 14-24.

1992. "Escrito en democracia. La literatura infantil y juvenil en castellano". Cuadernos de Literatura Infantil y Juvenil. Núm. 35: 7-19.

1998. La formación del lector literario. Madrid: Fundación Germán Sánchez Ruipérez.

Cubells et al. 1990. Corrientes actuales de la narrativa infantil y juvenil española en lengua castellana. Madrid: Asociación Española de Amigos del Libro Infantil y Juvenil.

Farias, Juan. 1990. "Realismo de la vida cotidiana”. En: Cubells et al., 67-71.

Fernández, V. 1991. "Panorama de la literatura infantil y juvenil española". Cuadernos de Literatura Infantil y Juvenil. Núm. 28: 13-22.

García Padrino, Jaime. 1992. Libros y literatura para niños en la España contemporánea. Madrid: Pirámide/Fundación Germán Sánchez Ruipérez.

1987. "La literatura infantil en la postguerra española (1939-1952): la difícil servidumbre de la literatura en la educación del niño". En: García Padrino et al., 111-34.

2000. "Clásicos de la literatura infantil española”. En: Cerrillo, Pedro y Jaime García 
Padrino (Coords.), 67-91.

García Padrino et al. Homenatge a Josep Vallverdú. Lleida, Institut d'Estudis Llercens.

Garralón, Ana. 2000. "La literatura infantil y juvenil desde ayer hasta hoy”. En: Garralón et al., 27- 36.

Garralón et al. XIII Jornadas de Animación a la Lectura. Ávila: Centro de Profesores y Recursos Arenas de San Pedro.

Gasol, Ana y Assumpciò Lissón. 1989. “Realismo... ¿con apellido?”. Cuadernos de Literatura Infantil y Juvenil. Núm. 4: 20-7.

Gómez del Manzano, Mercedes. 1987. El protagonista niño en la literatura infantil del Siglo $X X$. Madrid: Narcea.

Hendriks, María. 1990. España sí posee literatura infantil. M. O. Spaans. Rijks Universiteit Groningen.

Janer Manila, Gabriel. 1995. “Introducción”. La literatura infantil i la construcció d'Europa. Estudios Baleàricos. Núm. 52, junio - setiembre: 5-6.

Lage Fernández, Juan José. 1996. "La figura del maestro en la literatura infantil”. Amigos del Libro. Núm. 34: 43-50.

Lamo de Espinoza, E; R. Pardo y J. Tusell. (eds.). 1996. Entre dos siglos. Reflexiones sobre la democracia española. Madrid: Alianza.

Lluch, Gemma. 1998. "La comunicación literaria y el tipo de lector modelo que propone la actual literatura infantil". Ponencia leída en XII Jornadas de animación a la lectura, Arenas de San Pedro, Ávila.

Martínez, A. 1990. "La denuncia social en la literatura infantil”. En: Cubells et al., 85-9.

Martínez Cachero, José María. 1985. La novela española entre 1936 y 1980. Madrid: Castalia.

Merino, José María. 1990. "Pasado y novela”. En: Cubells et al., 55-9.

Nobile, Angelo. 1990. Literatura infantil y juvenil. Traducción Inés Marichalar. Madrid: Ministerio de Educación/Morata.

Rodríguez, Antonio Orlando. 1997. "La familia en la literatura infantil y juvenil contemporá- 
nea”. Revista de la Asociación Española de Amigos del Libro Infantil y Juvenil. XV (38): 38-40.

Rodríguez Aldecoa, Josefina. 1983. Los niños en la guerra. Madrid: Anaya.

Sierra i Fabra, Jordi. 1990. "Ciencia - ficción, la magia de lo fantástico o la realidad literaria de un futuro". En: Cubells et al., 37-43.

Sotomayor Sáenz, Victoria. 2000. "Lenguaje literario, géneros y literatura infantil”. En: Cerrillo, Pedro y Jaime García Padrino. (Coords.), 27-65.

Strausfeld, M. 1989. "El realismo crítico en la literatura infantil y juvenil". Cuadernos de literatura infantil y juvenil. Núm. 4: 83-7.

Valriu, Caterina. 1994. Història de la literatura infantil i juvenil catalana. Barcelona: Pirene Editorial.

1995. “Tendències actuals en la literatura infantil i juvenil catalana (1985-1995)". La literatura infantil i la construcció d'Europa. Estudios Baleàricos. 